\title{
Study Effect of Blood Glucose Level on Renal Failure in Peoples Suffering from Diabetes
}

\author{
A.L Basim M. Ali \\ Department of Chemistry, College of Science, Al-Kufa University, Iraq
}

\begin{abstract}
This study was accompanied in AL-Emam AL-Sajjsd hospital in al najaf al ashraf city through the period from May 2015 to September 2015. To evaluate serum lipid profile, albumin and $\mathrm{Hb}$ in patients, it involved 77 patients, 53 male and 24 females' patients, and their range of age from 21 to 65 years. The patient was identified as suffering (renal failure caused by diabetic) for both gender based on the history, clinical analysis test for renal function and DM. The control groups were 50; they were collected from medical staff and relatives who were free of kidney disease, diabetes and hypertension. Number of men is thirty and twenty women; the ages range btween twenty-two and sixty-six years. The samples of blood were take from the case (8-12) hours after night fasting, One of the most important causes that cause renal failure is diabetes by causing hurt to blood vessels in the organ (kidney) the units of filtering in the kidney are filled with small blood vessels. For along time, high glucose levels in the blood can cause narrow and clogged. The changes in parameters btween the levels in both male and female patients and their control, a positive significant change in (Uric acid, Blood glucose\{Sugar\}, Urea, Creatinine, K, PO4, GOT, GPT, Iron, Ferretin, TIBC, UIBC, TS\%, ETIBS) levels of male patients as compared with the control group, the same table states to negatively significant changing in levels of $(\mathrm{Ca}, \mathrm{Alb}, \mathrm{Hb}, \mathrm{PCV})$ in the tow gender patients with renal failure as paralleled with group of control. Just one item shows on significant change the item is Na when we compared with their control group. The effect of high blood sugar levels leads to many complications in vital human. There are no direct relationship between high blood sugar and diabetes on the hand versus the low level of hemoglobin or high level iron status on the other hand
\end{abstract}

Keywords: Renal failure, Diabetes mellitus, hyperglycaemia, Iron status, Hemoglobin

\section{Indroduction}

Diabetes is a extreme disease. It occurs when the body can not produce enough amount of insulin which is a hormone controls the amount of glucose in blood. Increase blood sugar level can cause problems in main parts of human body."Diabetes mellitus" (DM) is the keypurpose of "endstage renal disease" (ESRD). Contrariwise, "chronic renal failure" (CRF) is attendant with variant adaptations in metabolism of insulin and carbohydrate this definition described by. (Pedro Iglesias I and Juan J.2007), (Rabkin R, Ryan MP. 1984). (Schmekal B. 2002) explained that the modifications in the carbohydrate metabolism, especially chronic hyperglycaemia, ordinarily affect on renal function. For the time being, diabetic nephropathy appoints the greatestpublicreason of CRF.

Additionally the hyperperfusion (escalation in glomerular movement), hypertension and kidney"hypertrophy" are the main variation concomitant with high blood glucose (hyperglycaemia) in "diabetic nephropathy" this study produced by (Maeda M. Et al 2004). Also (Scholey Jw and Meyer TW.1989) expounded The "hypertension in glomerular capillary"detected in hyperglycaemia (DM) would represent to be a complications of the lack of insulin achievement as stern glycaemic control lower both kidney haemodynamic and renal size response Sundry moderators serve to preserve glomerular hyperfiltration associated with kidney damage. Many studies testified that perfect glycaemic dominance in the before dialysis is main in taminglong-standing assessment in (DM) patients on dialysis. Fine blood sugar control before dialysis was compact interconnected with morbidity (Heart disease, malnutrition and DM complications) this studies reported by (Morioka $T$ et al 2001), (Wu MS et al 1999). The relationship between high blood glucose and chronic renal failure and effect of glucose and microalbuminuria in damage of glomerulus as showen as in this schem. (Pedro Iglesias1 and Juan J.2007) and (Biesenbach G. Et al 2003)

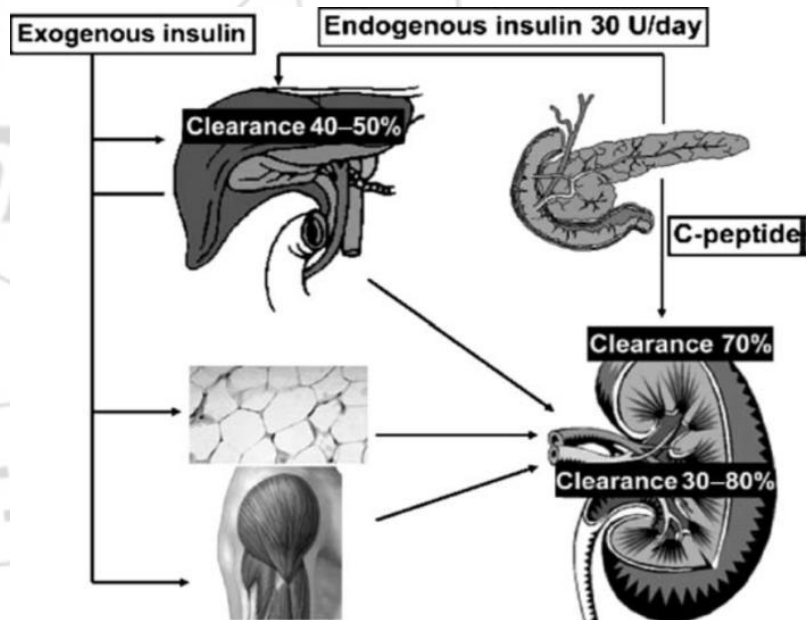

Figure 1: Schematic shows the relationship of insulin and its effects on the kidneys

\section{Subjects and Methods}

A-Patients: 77 patients, 53 male and 24 females patients, their range of age from 21 to 65 years These patients were accompanied in AL-Emam AL-Sajjsd hospital in al najaf al ashraf city, the patient was identified as suffering (renal failure caused by diabetic) for both gender based on the history, clinical analysis test for renal function and DM.

B-Controls: The control groups were 50; they were collected from medical staff and relatives who were free of kidney disease, diabetes and hypertension. 30 were males and 20 females, their ages range from 22 to 66 years. 


\section{International Journal of Science and Research (IJSR) \\ ISSN (Online) : 2319-7064}

Index Copernicus Value (2013) : 6.14 | Impact Factor (2015) : 6.391

C- Measurements: collection of blood sample from patients and control were take place in the morning in plain tubes then the serum separated by centrifugation. Determination of serum iron level were done by using Ferrozine colorimetric method (Artiss" et al, 1981), the colorimetry were used to estemate the Total Iron Binding Capacity (TIBC) in the following process this technique described by (Haematol, 1978) an overload of iron is added to the serum to flood the transferrin. The boundless iron is precipitated with (magnesium carbonatein) in basic medium, determine the supernatant iron after centrifugation.

Unsaturated iron-binding capacity (UIBC), theapotransferrin (amount of protein $)$ remains obtainable to link iron mathematically can be projected from the principle: UIBC $=$ TIBC - Sera of iron.

The ferritin quantifiable kit established on a (solid phase) (enzyme-linked immunosorbent assay) (ELISA) was provided by Monobind ${ }^{\circledR}$ Inc. USA. The analyze method uses anti-ferritin antibody from one rabbit for (solid phase) (microtitre wells) restriction and anti-ferritin antibody from a mouse monoclonal in the (antibody-enzyme horseradish peroxidase $)(\underline{\boldsymbol{H R P}})$ associated with solution.

Calculation of Estimated Total Iron Body Stores (ETIBS) by using the following equation (Rayssiguier., et al, 1991)

ETIBS $($ in $\mu \mathrm{mol})=($ sera ferritin in $\mu \mathrm{g} / \mathrm{L}) \times 143$

The percentage of transferrrin saturation (TS \%) was estimated by equation (Freeman \& Arneson, 2007) (11).

TS\% $=($ Sera Iron $\div$ TIBC $) \times \mathbf{1 0 0 \%}$

The following formula was used to calculate Transferrin concentration (Morgan' 1992):

Concentration of Transferrin $(\mathrm{g} / \mathrm{L})=\mathrm{S}$.Iron $(\mu \mathrm{mol} / \mathrm{L}) \div$ (TS percent. $\times 3.98)$

The formula is established on the highest bond of $2 \mathrm{~mol}$ $\mathrm{Fe}^{3+} / \mathrm{mol}$ of transferrin and a (molecular weight) of 79 , $570 \mathrm{gm} / \mathrm{mol}$ for transferrin. Sugar, Sodium, Uric acid, GOT, GPT, $\mathrm{Hb}, \mathrm{Na}, \mathrm{K}, \mathrm{Ca}$, Albumine and Serum Phosphate calculated Spectrophotometicaly.

\section{Results}

\begin{tabular}{|c|c|c|c|}
\hline Parameter & Patients & Control & P Value \\
\hline uric acid & $7.616 \pm 1.59$ & $5.8 \pm 0.842$ & $2.31 \mathrm{E}-10$ \\
\hline b sugar & $103.7218 \pm 144.7736$ & $95.43333 \pm 13.22141$ & 0.001208 \\
\hline Urea M $(\mathrm{mg} / \mathrm{dl})$ & $152.3774 \pm 42.76646$ & $30.65667 \pm 5.70648$ & $2.18 \mathrm{E}-27$ \\
\hline Crea M $(\mathrm{mg} / \mathrm{dl})$ & $8.128302 \pm 1.833175$ & $1.073333 \pm 0.204995$ & $1.03 \mathrm{E}-33$ \\
\hline na & $124.4906 \pm 10.52401$ & $129.8333 \pm 15.58311$ & 0.101147 \\
\hline k & $5.543396 \pm 1.4811$ & $3.953333 \pm 0.233021$ & $2.78 \mathrm{E}-10$ \\
\hline Ca mal & $7.658491 \pm 1.171034$ & $8.906667 \pm 0.28519$ & $4.58 \mathrm{E}-10$ \\
\hline Alb M (g/dl) & $4.049057 \pm 0.550392$ & $4.323333 \pm 0.45386$ & 0.016987 \\
\hline PO4 M (mg/dl) & $5.661132 \pm 1.909$ & $3.023333 \pm 0.419921$ & $7.32 \mathrm{E}-14$ \\
\hline Hb M & $9.720943 \pm 1.699206$ & $12.5 \pm 0.143839$ & $1.56 \mathrm{E}-16$ \\
\hline PCV M & $29.43717 \pm 5.042036$ & $46.56667 \pm 3.92765$ & $2.37 \mathrm{E}-27$ \\
\hline G OT M (U/L) & $30.03774 \pm 6.583669$ & $25 \pm 3.638871$ & $2.34 \mathrm{E}-05$ \\
\hline GPT M (U/L) & $28.9434 \pm 9.136602$ & $25.33333 \pm 6.834665$ & 0.044903 \\
\hline IRON M (g/dl) & $184.5843 \pm 105.8637$ & $85.76667 \pm 7.449524$ & $1.08 \mathrm{E}-08$ \\
\hline ferri M $(\mathrm{ng}$ ?ml) & $921.864 \pm 482.6929$ & $221.8333 \pm \pm 84.3233$ & $1.21 \mathrm{E}-14$ \\
\hline TIB M $(\mathrm{g} / \mathrm{dl})$ & $553.2013 \pm 305.7947$ & $275.7667 \pm 23.83808$ & $2.2 \mathrm{E}-08$ \\
\hline UIBC & $368.617 \pm 306.7646$ & $190 \pm 23.5621$ & $9.69 \mathrm{E}-05$ \\
\hline TS\% & $43.36877 \pm 39.93268$ & $31.31184 \pm 3.849689$ & 0.03364 \\
\hline ETIBS & $131826.6 \pm 69025.08$ & $31722.17 \pm 12058.23$ & $1.21 \mathrm{E}-14$ \\
\hline
\end{tabular}

Table (1) refers to the changes in parameters btween the levels of male patients and their control, a positive significant change in (Uric acid, Blood glucose\{Sugar\}, Urea, Creatinine, $\mathrm{K}, \mathrm{PO}_{4}$, GOT, GPT, Iron, Ferretin, TIBC, UIBC, TS\%, ETIBS) levels of male patients as compared with the control group, the same table states to negatively significant changing in levels of $(\mathrm{Ca}, \mathrm{Alb}, \mathrm{Hb}, \mathrm{PCV})$ male patients with renal failure as paralleled with group of control. just one item shows on significant change the item is $\mathrm{Na}$ when we compared with their control group. 


\section{International Journal of Science and Research (IJSR) \\ ISSN (Online) : 2319-7064}

Index Copernicus Value (2013) : 6.14 | Impact Factor (2015) : 6.391

\begin{tabular}{|c|c|c|c|}
\hline Parameter & Patients & Control & P Value \\
\hline uric acid & $6.14 \pm 1.00238$ & $5.38 \pm 0.67481$ & 0.004743 \\
\hline b sugar & $145.0417 \pm 72.69919$ & $109.55 \pm 13.36324$ & 0.027343 \\
\hline Urea M $(\mathrm{mg} / \mathrm{dl})$ & $137.7083 \pm 45.74835$ & $38.3 \pm 5.858866$ & $1.82 \mathrm{E}-10$ \\
\hline Crea M (mg/dl) & $8.045833 \pm 1.762898$ & $1.125 \pm 0.219749$ & $6.13 \mathrm{E}-16$ \\
\hline na & $136.4583 \pm 8.652615$ & $140.25 \pm 7.738319$ & 0.132695 \\
\hline k & $6.391667 \pm 1.381215$ & $4.72 \pm 0.39683$ & $4.97 \mathrm{E}-06$ \\
\hline Ca mal & $8.075 \pm 1.551787$ & $8.875 \pm 0.429044$ & 0.022632 \\
\hline Alb M (g/dl) & $3.93125 \pm 0.594243$ & $4.33 \pm 0.426861$ & 0.013429 \\
\hline PO4 M (mg/dl) & $5.3125 \pm 1.247799$ & $3.875 \pm 0.253138$ & $9.71 \mathrm{E}-06$ \\
\hline Hb M & $9.20625 \pm 1.537787$ & $13.125 \pm 0.369744$ & $3.39 \mathrm{E}-12$ \\
\hline PCV M & $27.31875 \pm 4.230864$ & $40.65 \pm 3.216323$ & $6.05 \mathrm{E}-15$ \\
\hline G OT M (U/L) & $29.125 \pm 5.1187$ & $23.25 \pm 5.514335$ & 0.000795 \\
\hline GPT M (U/L) & $26.29167 \pm 4.731754$ & $22.5 \pm 6.27023$ & 0.032506 \\
\hline IRON M (g/dl) & $167.8346 \pm 87.75233$ & $102.15 \pm 26.97811$ & 0.001677 \\
\hline ferri M (ng?ml) & $895.9294 \pm 323.432$ & $183.25 \pm 51.09421$ & $1.22 \mathrm{E}-10$ \\
\hline TIB M (g/dl) & $478.964 \pm 270.72$ & $334.7 \pm 28.79163$ & 0.016065 \\
\hline UIBC & $311.1294 \pm 285.1446$ & $232.55 \pm 42.04068$ & 0.19502 \\
\hline TS\% & $57.85999 \pm 73.69779$ & $30.80748 \pm 8.616051$ & 0.087253 \\
\hline ETIBS & $128117.9 \pm 46250.77$ & $26204.75 \pm 7306.472$ & $1.22 \mathrm{E}-10$ \\
\hline
\end{tabular}

Table (2) refers to the changes in parameters btween the levels of female patients and there control, a positive significant change in (Uric acid, Blood glucose \{Sugar\}, Urea, Creatinine, K, PO4, GOT, GPT, Iron, Ferretin, TIBC, UIBC, TS\%, ETIBS) levels of mle patients as compared with the control group, the same table states to negatively significant changing in levels of $(\mathrm{Ca}, \mathrm{Alb}, \mathrm{Hb}, \mathrm{PCV})$ male patients with renal failure as paralleled with group of control. Just one item shows on significant change the item is $\mathrm{Na}$ when we compared with their control group.

\begin{tabular}{|c|c|c|c|}
\hline Parameter & Male Patients & Female Patients & P Value \\
\hline uric acid & $7.616792 \pm 1.592127$ & $6.14 \pm 1.00238$ & $5.68 \mathrm{E}-06$ \\
\hline b sugar & $144.7736 \pm 103.7218$ & $145.0417 \pm 72.69919$ & 0.984808 \\
\hline Alb M (g/dl) & $152.3774 \pm 42.76646$ & $137.7083 \pm 45.74835$ & $6.08 \mathrm{E}-13$ \\
\hline Urea M (mg/dl) & $8.128302 \pm 1.833175$ & $8.045833 \pm 1.762898$ & $2.2 \mathrm{E}-30$ \\
\hline Crea M (mg/dl) & $124.4906 \pm 10.52401$ & $136.4583 \pm 8.652615$ & $1.73 \mathrm{E}-29$ \\
\hline $\mathrm{Na}$ & $5.543396 \pm 1.4811$ & $6.391667 \pm 1.381215$ & $2.33 \mathrm{E}-59$ \\
\hline $\mathrm{K}$ & $7.658491 \pm 1.171034$ & $8.075 \pm 1.551787$ & $3.34 \mathrm{E}-08$ \\
\hline Ca mal & $4.049057 \pm 0.550392$ & $3.93125 \pm 0.594243$ & $1.85 \mathrm{E}-29$ \\
\hline $\mathrm{PO} 4 \mathrm{M}(\mathrm{mg} / \mathrm{dl})$ & $5.661132 \pm 1.909$ & $5.3125 \pm 1.247799$ & 0.343763 \\
\hline $\mathrm{Hb} \mathrm{M}$ & $9.720943 \pm 1.699206$ & $9.20625 \pm 1.537787$ & 0.194384 \\
\hline PCV M & $29.43717 \pm 5.042036$ & $27.31875 \pm 4.230864$ & 0.061129 \\
\hline G OT M (U/L) & $30.03774 \pm 6.583669$ & $29.125 \pm 5.1187$ & 0.511615 \\
\hline GPT M (U/L) & $28.9434 \pm 9.136602$ & $26.29167 \pm 4.731754$ & 0.098292 \\
\hline IRON M (g/dl) & $184.5843 \pm 105.8637$ & $167.8346 \pm 87.75233$ & 0.471038 \\
\hline ferri M (ng?ml) & $921.864 \pm 482.6929$ & $895.9294 \pm 323.432$ & 0.782537 \\
\hline TIB M (g/dl) & $553.2013 \pm 305.7947$ & $478.964 \pm 270.72$ & 0.289987 \\
\hline UIBC & $368.617 \pm 306.7646$ & $311.1294 \pm 285.1446$ & 0.427664 \\
\hline TS\% & $43.36877 \pm 39.93268$ & $57.85999 \pm 73.69779$ & 0.372846 \\
\hline ETIBS & $131826.6 \pm 69025.08$ & $128117.9 \pm 46250.77$ & 0.782537 \\
\hline
\end{tabular}

Table (3) shows the difference in levels of all parameters between male patients and female patients, the results appear a significant difference in the following criteria, (Uric acid, Albumin, Urea, Ca) this items are showing Significant increase in the proportion of male patients to female patients, while the items (Creatinine, $\mathrm{Na}, \mathrm{K}$ ) are performing Significant increase in the level of female patients as compare as to level of male patients, 


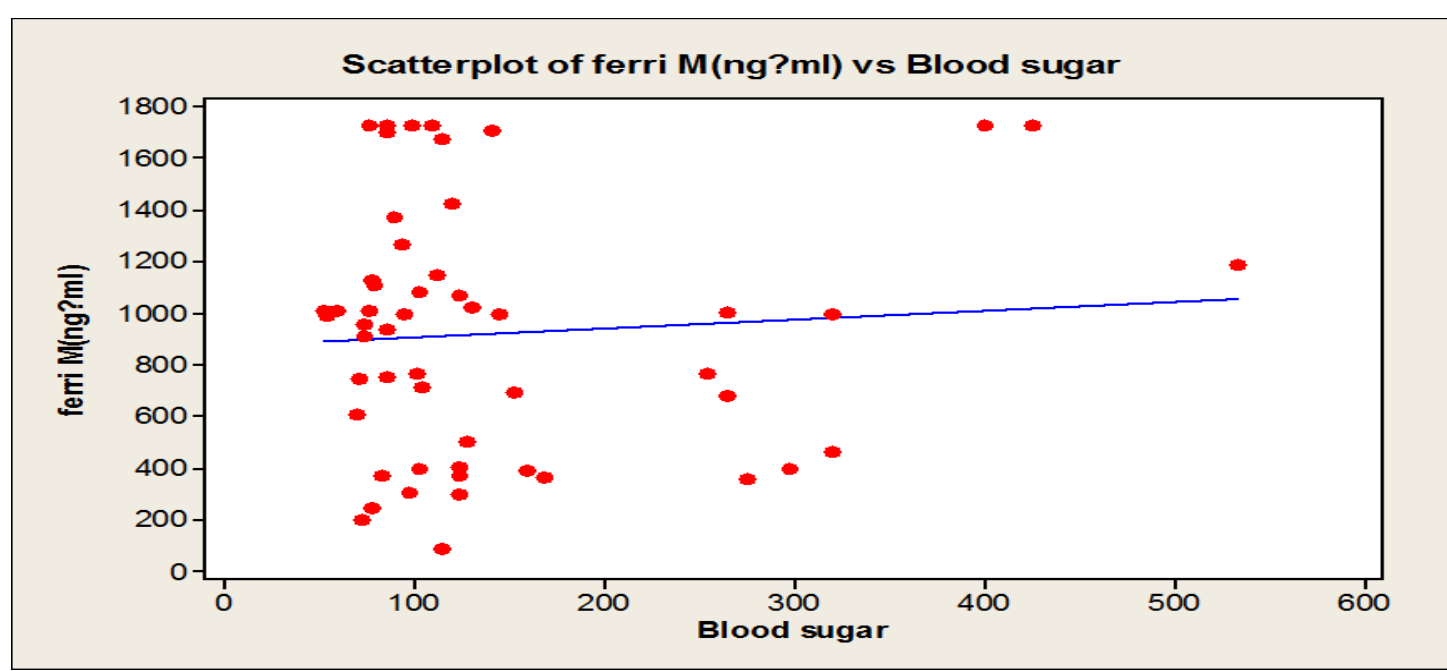

Figure 1: The regression between Blood Sugar \& Ferretine in male patients with CRF

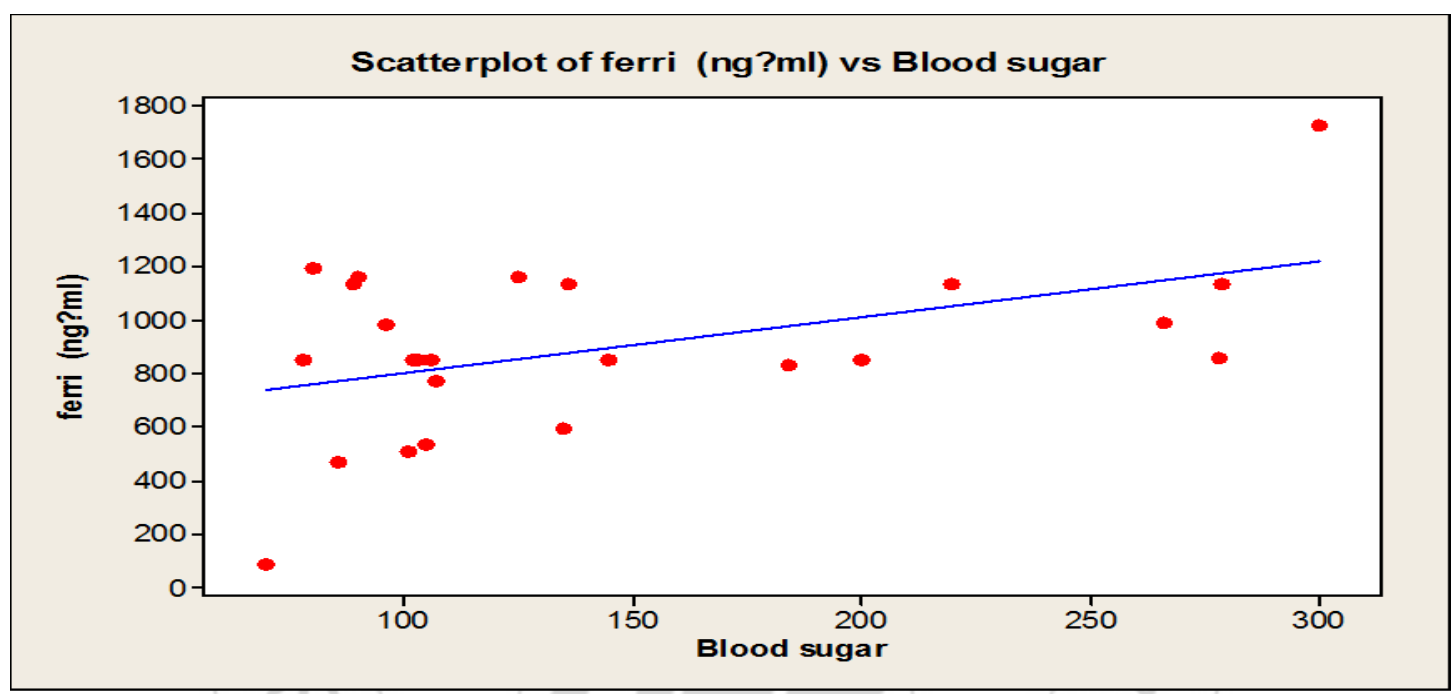

Figure 2: The regression between Blood Sugar \& Ferretine in female patients with CRF

The result in Figure (1) \& (2) appear a positive correlation between Blood sugar level and Ferretine level in male \& female patients with CRF respectively.

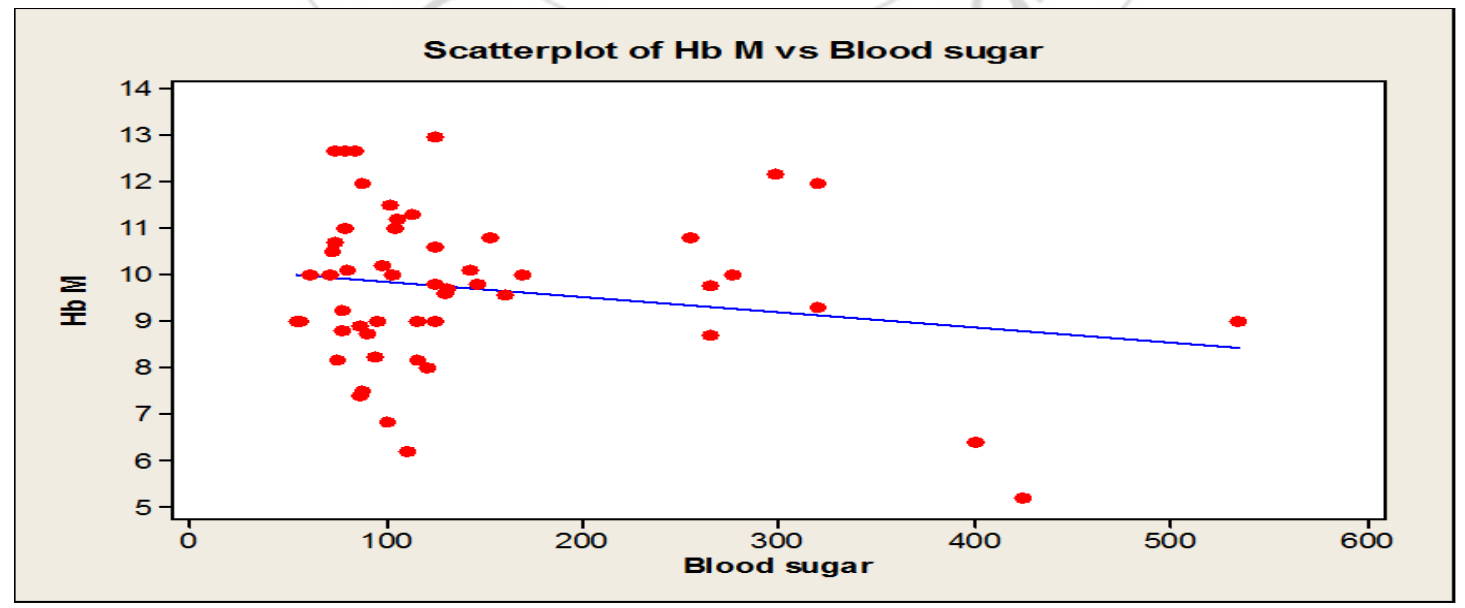

Figure 3: The regression between Blood Sugar \&Hb in male patients with CRF 


\section{International Journal of Science and Research (IJSR) \\ ISSN (Online) : 2319-7064}

Index Copernicus Value (2013) : 6.14 | Impact Factor (2015) : 6.391

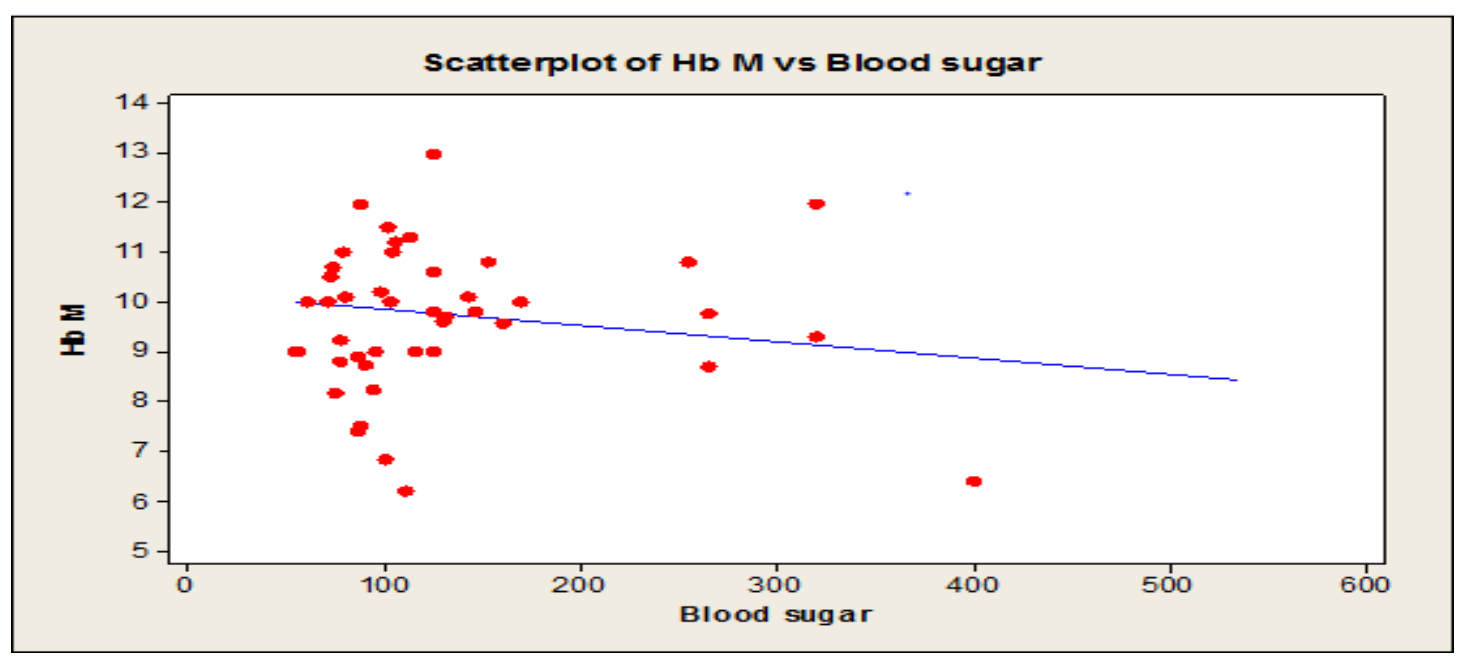

Figure 4: The regression between Blood Sugar \&Hb in female patients with CRF

The result in Figure (3) \& (4) explain a positive correlation between Blood sugar level and $\mathrm{Hb}$ level in male \& female patients with CRF respectively.

\section{Discussion}

The results in this study (table $1 \& 2$ ) shows high level of blood sugar in all male \& female patients with CRF, increase blood glucose is affect on glomerulus (damage of glomerulus) because the increase level of glucose due to be interconnected to the increase of microalbuminuria which is disturb the renal function, the mostly common causes of CRF is diabetic nephropathy, based from increasing the glomeruler flow (hyperperfusion) in the other handn the hypertrophy variations related with high blood glucose in diabetic nephropathy that is agree with (Hostetter TH et al 1982), (Maeda M. Et al 2003) which is explain the same as in the current results in addition the results and phenomenons is agree with many studies as well as (coward et al 2005) who explain the relationship between high blood glucose and chronic renal failure and effect of glucose and microalbuminuria in damage of glomerulus, in addition There are numerous research that supports the current study such as (Wkly Rep 2005), (Hostetter TH et al 1982), (Maeda M. Et al 2003) all of these researchers gather similar consequences to the results obtained in the present research, they proved that the correlation among glucso (high blood glucose), (nephropathy) and (glomeruler flow).

By the way the rest of the results in the current study, a lot of research that prove the relationship imbalance that occurs in the levels of electrolytes with kidney failure disease from the study which is agree with the current research (A. J. Kadhum 2008)

The kidneys make an essential hormone named erythropoietin (EPO). Responsible for formation of the red blood cells, the hormone is secreted from kidney, EPO makes red blood cells. If you have renal disease, it cannot make adequate EPO. The RBCs count to drib and anemia to improve. This explanation is congruous with the current resuls as shown as in table $(1 \& 2)$ wich is agreed with (Michael Hsieh and David A Power 2009)
Table (1 and 2) shows the rising the levels of all iron status in male and female patients with $\mathrm{CRF}$, requirement iron enhancements and EPO to promotion their $\mathrm{RBC}_{\mathrm{s}}$ total to a level that will diminish the prerequisite for $\mathrm{RBC}_{\mathrm{s}}$ "transfusions", iron and EPO will develop the signs of anemia, by the way in CRF the kidney can not provide EPO Adequately Iron available but without erythropoietin production due to lack of nephropathyleading to a high level of iron in the blood, in addition the ferritin level helps evaluate the extent of " iron stored" in the human body, ferritin rises with high iron or increase existence kidney infections this resuls is agree with $(\mathrm{Dr}$ Donald Richardson2014)

Table (3) shows the difference in the levels betweem male and female parameters in patients with CRF Almost all the readings came within the expected for most of the previous research as well as (David S. Baldwin et al 2015)

The results that is showen in the figures $(1,2$, 3and4) the positive correlation between sugar and frretin in male and female in CRF patients and negative correspondence between glucose and $\mathrm{Hb}$ in both male and female CRF patients theexpectancy results of the relationship of the forms mentioned in the aforementioned relationship is indirect, as the diabetic directly affecting in the renal functions wich is cause the anemia, thus, increase iron level and blood sugar in the same way decrease $\mathrm{Hb}$ level this results is agree with (coward et al 2005), (coward et al 2005) and (Maeda M. Et al 2003).

\section{Conclusions}

Through Current study there are many conclusions from the most important of which is the effect of high blood sugar levels leads to many complications in vital human. There are no direct relationship between high blood sugar and diabetes on the hand versus the low level of hemoglobin or high level iron status on the other hand. Of the commandments of the Imam Ali, peace be upon him (got away from the two white things after the thirty-fifth) the mean salt and sugar should be careful of the sugar because it involves serious consequences. 


\section{International Journal of Science and Research (IJSR) \\ ISSN (Online) : 2319-7064}

Index Copernicus Value (2013) : 6.14 | Impact Factor (2015) : 6.391

\section{Acknowledgments}

This modest work geared to support human category, which suffer from chronic diseases, I wish to commend the patients who participated and understand the value of work, The authors wish to thank all the thalassemic patients who participated in this study; clinical laboratory of at "ALEmam AL-Sajjsd hospital " in Najaf city, (Iraq) for execution the laboratory analyses.

\section{References}

[1] (A. J. Kadhum Antioxidant and lipidperoxidation in chronic renal failure patients Coll.of Sci./Univ.of AlQadisyia AL-Qadisiya Journal of Vet. Med. Sci. Vol. 17 No./ 2 2008)

[2] (David S. Baldwin, MD: A Legacy in Nephrology Paul L. Kimmel, Joel Neugarten, and Jerome Lowenstein JASN March 2015 26: 531-535; published ahead of print August 22, 2014, doi:10.1681/ASN.2014030305)

[3] (Dr Donald Richardson, Consultant Nephrologist, York District Hospital NIH Publication No. 14-4619 May 2014)

[4] (Michael Hsieh, David A Power bnormal Renal Function and Electrolyte Disturbances in Older People J Pharm Pract Res 2009; 39: 230-4)

[5] (Pedro Iglesias1 and Juan J. D1'ez2Insulin therapy in renal disease Department of Endocrinology, Hospital General, Segovia, Spain.Department of Endocrinology, Hospital Ramón y Cajal, Madrid, Spain) 0.1111/j.1463-1326.2007.00802.x.

[6] Artiss JD, Vinogradov S, Zak B. Spectrophotometric study of several sensitive reagents for serum iron.Clin Biochem. 1981;14:311-315. [PubMed]

[7] Biesenbach G, Raml A, Schmekal B, Eichbauer-Sturm G. Decreased insulin requirement in relation to GFR in nephropathic type 1 and insulin-treated type 2 diabetic patients. Diabet Med 2003; 20: 642-645

[8] Centers for Disease Control and Prevention (CDC). Incidence of end-stage renal disease among persons with diabetes - United States, 1990-2002. MMWR Morb Mortal Wkly Rep 2005; 54: 1097-1100.

[9] Centers for Disease Control and Prevention (CDC).Incidence of end-stage renal disease among persons with diabetes - United States, 1990-2002. MMWR

[10] Coward RJ, Welsh GI, Yang J et al. The human glomerular podocyte is a novel target for insulin action. Diabetes 2005; 54: 3095-3102.

[11] Freeman V, Arneson W. Hemoglobin production, disorders, and testing. In: Anderson W, Brickell J, editors. Clinical Chemistry: A Laboratory Prospective. Philadelphia: FA Daves Co.; 2007. p. 185.

[12] Hostetter TH, Rennke HG, Brenner BM. The case for intrarenal hypertension in the initiation and progression of diabetic and other glomerulopathies. Am J Med 1982; 72: 375-380.

[13] Iron Panel of the International Committee for Standardization in Hematology The measurement of total and unsaturated iron-binding capacity in serum. Br J Haematol. 1978;38:281-290. [PubMed]
[14] Maeda M, Yabuki A, Suzuki S, Matsumoto M, Taniguchi K, Nishinakagawa H. Renal lesions in spontaneous insulin-dependent diabetes mellitus in the nonobese diabetic mouse: acute phase of diabetes. Vet Pathol 2003; 40: 187-19

[15] Maeda M, Yabuki A, Suzuki S, Matsumoto M, Taniguchi K, Nishinakagawa $H$. Renal lesions in spontaneous insulin-dependent diabetes mellitus in thenonobese diabetic mouse: acute phase of diabetes. Vet Pathol 2003; 40: 187-195.]

[16] Morb Mortal Wkly Rep 2005; 54: 1097-1100

[17] Morgan EH. Transferrin. In: Haeberli A, editor. Human Protein Data, Part B. Weinheim: Wiley-VCH; 1992. p. 291.

[18] Morioka T, Emoto M, Tabata T et al. Glycemic control is a predictor of survival for diabetic patients on hemodialysis. Diabetes Care 2001; 24: 909-913.]

[19]Rabkin R, Ryan MP, Duckworth WC. The renal metabolism of insulin. Diabetologia 1984; 27: 351-357.

[20]Rayssiguier Y, Mbega JD, Durlach V, et al. Mgnesium and blood pressure. I. Animal studies. Book of abstracts VIth International $\mathrm{Mg}$ Symposium abstracts. Indore, India, Dec 2-6, 1991.

[21] Scholey JW, Meyer TW. Control of glomerular hypertension by insulin administration in diabetic rats.J Clin Invest 1989; 83: 1384-1389].

[22] Wu MS, Yu CC, Wu CH, Haung JY, Leu ML, Huang CC. Pre-dialysis glycemic control is an independent predictor of mortality in type II diabetic patients on continuous ambulatory peritoneal dialysis. Perit Dial Int 1999; 19 (Suppl. 2) : S179-S183.] 